\title{
Tasting Wine Making Territories ${ }^{1}$
}

\author{
Andrea Mubi Brighenti
}

\section{Introduction}

This chapter explores the intersections between the activity of wine tasting and the law. Certainly, wine is an extremely legislated object. However, not only does law operate on wine 'from the outside', but there is also a special law that is secreted by wine itself in its social life. While the social life of wine can be observed in a multiplicity of sites, the moment of tasting may illuminate some interesting facets of the problem. How can wine tasting develop its own inner law? This is the driving question of this chapter. The theoretical lens to tackle the question is territoriology, i.e., a general science of territorial formations. The notions of animism and constitutionalism are also employed as two tools to bring to light the ways in

${ }^{1}$ I wish to thank Andrea Pavoni and two anonymous reviewers for their comments on a previous version of this text, and for their encouragement to improve my work. Limitations are my own. 
which territories are forged and elaborated. The judgement of a wine, especially in public performances, is a subtle activity where this special material is interrogated following the lines of its own expressiveness. Instead of a post-humanist legal insight, what is reflected upon here is the way tasting produces 'modalisations' that animate wine at the same time as they seek to assess and evaluate it. Here, the law can thus be observed as generated immanently, in the activity and the materials it is supposed to judge. The law emerges as a form of encounter in the territorialisations laid out and shaped by the dynamic of the encounter itself.

\section{Pleading Animism as a Theoretical Alternative to Post-Humanism}

Post-humanism is a premature ideal, given that we don't have a clue of what the human is in the first place. ${ }^{2}$ However, it is a matter of everyday experience that humans have moments when they become non-human. Not only this, but the way in which humans reach out for each other (what is also called 'society') occurs precisely through similar moves. As the anthropologist Marcel Mauss saw clearly, human society is a vast domain of circulations, and there is no other way for humans to associate with others except through the range of non-human materials to be fashioned and passed on, of things given and

2 '.. and then the clouds break, and we see how, with the rest of nature, we are straining towards man, as towards something that stands high above us.' Friedrich Nietzsche, Untimely Meditations (Cambridge: Cambridge University Press, 1997[1876]), \$III: 5. 
taken. These things we also call media. Most notably, and contrary to what often believed, the things that mediate us are never inert objects; instead, they are alive. They are us, they are our non-human becoming that enables us to be human with others. That is why Maussian sociology is, at bottom, animistic. ${ }^{3}$ According to this point of view, people and things appear as terrains, events, encounters that is, impossible to set apart.

This is why animism may be a better word for the insight post-humanism claims to encapsulate. While it is impossible to develop a whole theory of animism here, the type of approach that is endorsed draws from authors who have recently attempted to revive vitalism, such as Jane Bennett, Tim Ingold and more particularly, Mattias Kärrholm in his analysis of the work of the modernist architect Louis Kahn and the Brazilian writer Clarice Lispector. ${ }^{4}$ In various ways, recent scholarship has suggested that animism is a perfectly normal attitude and a common procedure in contexts where we do not master all the variables and entities at play (which is, after all, in

3 Marcel Mauss, Sociologie et anthropologie (Paris: Puf, 1950). In his early discussion of Mauss' work, Lévi-Strauss severely castigated this animistic penchant in his French predecessor. But, perhaps, animism found the most suitable place to survive right at the heart of structuralism. Certainly, in retrospect, one may conjecture that modernism was in the end more animistic than post-modernism. In architecture, for instance, this becomes particularly striking when one examines closely the work of Le Corbusier or Louis Kahn. See Mattias Kärrholm, 'The Animistic Moment. Clarice Lispector, Louis Kahn and a Reassembling of Materialities', lo Squaderno 39 (2016).

${ }^{4}$ See Jane Bennett, Vibrant Matter: A Political Ecology of Things (Durham, NC: Duke University Press, 2009), Tim Ingold, Being Alive (London: Routledge, 2011) and Kärrholm, 'The Animistic Moment'. 
most cases of our life). In these contexts the subject and the object, instead of standing in front of each other as they are supposed to be, and required to be - become enmeshed in hybrid terrains. As noted by Kärrholm, the animistic attitude consists of 'the animation of an actor with a face or a body'. In other words, animism concerns specific situations or peculiar 'moments' when things are brought to have faces so that the involved bodies become animate. ${ }^{5}$ The ensuing situation is one that 'entails the becoming of a living and moving body, a figuration, that also figurates my body or other associated bodies' ${ }^{6}$

In the following text, an attempt is made to show how animism may help explaining the experience of wine tasting. To this aim, wine tasting is observed as a form of territory-making. In turn, territories are conceptualised through the lens of territoriology, i.e. a general or enlarged science of territories devoted to study the life of human animals - among others - as they consociate, thanks to special formations that carry them literally 'beyond themselves'. As a science of social life, territoriology is necessarily dynamic, attentive to territory making acts that occur through territorial stabilisations, transformations, transductions, abductions, evictions, etc. ${ }^{7}$

5 The notion of 'facialisation' or face-making is extensively developed by Deleuze and Guattari and provides an important background for my whole discussion. See Gilles Deleuze \& Félix Guattari, Mille Plateaux (Paris: Minuit, 1980).

${ }^{6}$ Kärrholm, 'The Animistic Moment', 75.

7 See Andrea Mubi Brighenti, 'On Territorology. Towards a General Science of Territory', Theory, Culture \& Society 27(1) (2010) and Mattias Kärrholm, 'The Materiality of Territorial Production a Conceptual Discussion of Territoriality, Materiality, and the Everyday Life of Public Space', Space and Culture 10(4) (2007). 
Territories are not just explored - they are explorations. Conversely, there is no exploration that is not territorial: study is reconnaissance, wayfaring. Territories are as much spatial as they are temporal; they are as much material as they are expressive. ${ }^{8}$ Engagement, temporality, protraction, fidelity, stubbornness are just some of the dimensions in which territories come to exist and persist. In its territorial embodiments, social life takes place in the element of the visible, the sensible 'fabric' where humans and things meet and become interwoven. And the visible can never be dissociated from a sayable in statu nascendi - in other words, the visible evokes endless visibilisations that derive from the ways in which materials are arranged, tools employed, meetings imagined and carried out. ${ }^{9}$

These facts are palpable (better, palatable) in the experience of tasting. Of course, for the sociologist, who has pledged alliance to the Weberian Wertfreiheit, hedonistic consumption of whichever substance may retain its moral legitimacy (regardless of the fact that Weber himself did not particularly like hedonists). However, it is in an intermediate position between sheer, 'mute, or 'dumb' hedonism (drinking in order to get drunk) and a purely 'formal-rational', 'commercial' knowledge of products (being an expert in wine classifications and brands) that

${ }^{8}$ Andrea Mubi Brighenti and Mattias Kärrholm, 'Three Presents: On the Multi-temporality of Territorial Production and the Gift from John Soane', Time \& Society (2016).

9 Andrea Mubi Brighenti, 'The Visible', Frontiers in Sociology (2017), https://www.frontiersin.org/articles/10.3389/fsoc.2017.00017/full 
the complex, animistic territory of tasting opens up. ${ }^{10}$ Territories have their law - a living law which could also be called a 'constitution. ${ }^{11}$ Contrary to what usually held, a constitutional approach provides the most detailed, concrete, and microscopic analysis of law. ${ }^{12}$ Understood as radical legal pluralism, constitutionalism 'frees the legal imagination from structuralist thinking; it frees legal conceptions of normativity from the assumptions of Weberian formal-rationality; and it frees legal notions of relationships from their anchorage in official institutions of third-party dispute resolution. ${ }^{13}$

An attempt is made here to show that constitutionalism and animism may be helpful tools in the study of territorial practices. The following theoretical reflections derive from a previous ethnographic study of sommeliers as qualified taste guides. ${ }^{14}$ The experience of tasting was

${ }^{10}$ While in theory all drinkable liquid can be tasted (including, for instance, whisky, honey, olive oil, coffee, tea, water etc.), for histori$\mathrm{cal}$, commercial, and cultural reasons, the tradition of wine tasting is the one where the most refined terminology and a wide-ranging systematics has developed.

${ }^{11}$ I have explored this nexus between law, territory and constitutionalism in Andrea Mubi Brighenti, 'On Territory as Relationship and Law as Territory', Canadian Journal of Law and Society/Revue Canadienne de Droit et Société 21(2) (2006).

${ }^{12}$ See for instance Roderick A. Macdonald, Lessons of Everyday Law (Montreal: McGill-Queen's University Press, 2002).

${ }^{13}$ Roderick A. Macdonald, 'Metaphors of Multiplicity: Civil Society, Regimes and Legal Pluralism', Arizona Journal of International \& Comparative Law 15(1) (1998): 71.

${ }^{14}$ A commissioned research carried out in 2007-8, mainly in Central and Northern Italy. Funded by the Italian Ministry of Research and University under the project Ethnography of Professional Communities and Expert Knowledge coordinated by Prof Giolo Fele at the University of Trento. 
then mainly observed as a type of public performance. A number of observations were carried out at events where professional and semi-professional sommeliers met to taste and debate wines from specific regions (wines from Jura, wines from Marche...) or specific grapes (nebbiolo, sagrantino...). As sommeliers were discussing wines, it appeared clear that tasting has to do with probing and simultaneously shaping the territorial constitution of the encounter with a given wine in a shared, public domain. Also noteworthy is the fact that wine is increasingly ingrained in the official presentation and imagination of territories: it confers value to territories. Blind tasting session are increasingly organised as not only contests but also tourist attractions for marketing purposes. ${ }^{15}$ This way, the 'internal constitution' ends up doubling the external one, and the law of the state which surrounds the production and distribution of wine is in its turn covered by the law of wine.

In this context, it is also interesting to observe how taste appears as simultaneously one-dimensional - insofar as it surely represents a form of passion, fixation, even mania and $\mathrm{n}$-dimensional - in the sense that this experience quickly evolves into an increasingly rich, nuanced, unique territory of relations and their history, a territory that ultimately forms the atmosphere in which tasters find their own location as well as their way. This way,

${ }_{15}$ One may land for instance in Rome for a scientific conference and end up at a featured tasting session where a local sommelier, making his best efforts to speak a passable English, showcases the five most famous Italian wines trying to depict a snap 'portrait of Italy' and its landscapes. 
the landscape affects the viewer who regards it. A sort of animistic effect ensues, whereby territorial constitutions can never be successfully reduced to 'orthogonal', subjectobject relations, but must be disassembled and probed as rounded, evolving formations.

\section{Judging Wine}

What is it that we actually drink, Antoine Hennion asked provocatively: a liquid, a label or a price? ${ }^{16}$ 'During a nice dinner in the company of friends, a glass of wine can create a moment of merry conviviality. Wine tasting, however, is a different thing. Such an austere remark, written almost in the register of an admonishment, can be found in the opening page of a classic tasting textbook by the Italian Sommelier Association. Similar, more or less explicit, remarks are not uncommon among sommeliers. In the first place, sommeliers need to distinguish themselves from people who merely 'enjoy wine' - here is a first assertion of legal pluralism, namely, cutting out the jurisdiction. Yet, some sort of enjoyment is certainly involved in tasting. At first, one might be tempted to oppose the company of a 'merry glass of wine' and the activity of 'wine tasting' as one would oppose convivial pleasure, on the one hand, and intellectual pleasure, on the other. While this view is not entirely wrong, for it to make sense, the expression 'intellectual pleasure' must be understood correctly.

${ }^{16}$ Antoine Hennion, Qu'est ce qu'un bon vin? Ou, comment intéresser la sociologie à la valeur des choses (Paris: Centre de Sociologie de l'innovation. Working Paper 15, 1 March 2015). 
First, we are not dealing with the difference between a social and a solitary activity, given that tasting is always a social activity. Early on in her training, the neophyte taster is recommended never to taste alone. This is essentially for two reasons: on the one hand, an aesthetic-moralistic one - 'it is not nice' - on the other, no less remarkably, an epistemological one - 'exchange of views is necessary.' In this sense, even when two colleagues or friends perform a tasting session, we are already dealing with a form of public experience and the specific visibilities conveyed by it.

Second, 'intellectual activity' is not meant in a loose, everyday sense as an alias for non-manual occupations. Instead, it is taken as pertaining to a form of practice specifically related to the production of judgements. What contradistinguishes wine tasting is the expression of taste judgements. On the one hand, judgement is certainly tied to a whole universe of publicness, visibility and accountability. As such, it is intimately linked to legal discourse via the production of justifications, and the mobilisation of repertoires of justification. ${ }^{17}$ As soon as one describes a wine, one also becomes accountable to an extended series of rules and protocols, as well as background knowledge, normative expectations and so on. One can best feel the weight of judgement when, as a novice, one is asked to present a wine and comment upon it. It is a bit like learning to walk, but also at the same time like learning the right answer from the school textbook. In a sense, the right

${ }^{17}$ Luc Boltanski and Laurent Thévenot, On Justification: Economies of Worth (Princeton, NJ and Oxford: Princeton University Press, 2006[1991]). 
answer is already there as the technique that enables one to walk, despite the fact that we all walk differently. The formulation of a judgement puts tasters in the domain of semiotic investigation: indisputably, wine emits signs. What do these signs mean? How to make sense of them? How to adequately capture the uniqueness of this wine? How to legitimate my interpretive hypothesis? How can I defend my thesis in front of other tasters? Such public judgements are simultaneously technical, normative, legal and, more amply understood, moral and political (in that, following radical constitutional pluralism, pure formal rationality is a luxury we cannot afford).

But interestingly, sommeliers tend to reject all terms and phrasing concerning 'judgement'. Why is it so? The fact is that they are running a campaign for 'objectivity'. Tasting, sommeliers argue, should not be reduced to a matter of personal taste (de gustibus); what should be at stake is the 'objective analysis of the sensations' produced by wine on one's sensory apparatus. In the technical vocabulary developed by sommeliers, the evaluative aspects, such as the formulation of judgements concerning the quality, harmony and evolution of a wine, must play a subordinate role and, above all, they must only be formulated after a complete and accurate description and analysis of the wine just tasted has been carried out.

Certainly, organoleptic or 'sensory' analysis is different from chemical analysis, also known as 'instrumental' analysis (i.e. analysis conducted with technological means of detection), such as, for example, a gas chromatography. Sommeliers know quite well that, by making use of their sense organs, they can only hope to achieve 
measures that are quantitatively less precise than those revealed by a technical apparatus. Nevertheless, they do not regard this fact as compromising objectivity, least as an impediment to their work. Sommeliers have developed the distinction between, on the one hand, a list of quantitative elements and, on the other, the ability to spot and express the unity (the 'proper quality') of a given wine (sometimes, also referred to as its 'atmosphere'). A refrain often heard in the community of sommeliers is that, after all, it is humans, not machines, who eventually drink the wine: consequently, producing an ensemble of quantitative measurements can only have industrial applications, but is insufficient to render an accurate analysis. The latter can only be attained when one can claim to have 'understood' a certain wine - when one has captured its evanescent Stimmung. In this sense, recognising the presence of a subject and admitting its importance to organoleptic analysis are not considered by sommeliers as hampering well-balanced analysis - to the extent that the subject, as they say, does not 'prevaricate' the operation by producing 'idiosyncratic' statements. In short, professional sommeliers conceptualise the activity of tasting as an encounter between a subject and an object that should be resolved in favour of the latter: what counts, in their view, is the object, and the revelation - or the appearing, the explicitation, the becoming-explicit - of its features.

\section{Understanding the Modes of Expression}

However, this image, pivoted around the relationship established between an investigating subject and an 
investigated object is not entirely adequate to account for the practice of wine tasting as a public, visible undertaking. Indeed, by describing wine as a mere object upon which a certain analytical activity is performed, one would not be able to understand much of sommeliers' professional working practices. The image of wine as an object misleads us into a kind of deterministic conception which deteriorates into either a search for causal mechanisms of chemical molecules combinations, or on the contrary - but with comparable reductionist outcomes - a radical social constructivism where an equally simplistic activity of truth construction by consensus is envisaged. Which are, then, the actual ways in which wine has a voice in the activity of tasting?

Wine is neither a subject nor an object. Instead, it could be better appreciated as an expressive material, or a mode of being that emerges and takes shape in the context of the practice of tasting. The specific nature of encounters with wine lies in a double articulation, always simultaneously material and expressive. Taking inspiration from Spinoza's substantiae affectio, a mode can be described as precisely the outcome of an encounter, a meeting of agents and reagents (chains of wine-glass-nose-mouthlight-fellow tasters...), a complex composition of distributed variables within a continuum of heterogeneous elements that stretch into each other. The series of nexuses and links established by these 'prolongations' is of neither casual nor causal nature. The 'grip' or 'catch' that certain elements exercise upon others endures only until these configurations remain active, effectuated in practice. And this happens until agents act upon each other 
and react to each other by selecting and capturing certain qualities that can be appropriated from the material itself. In short, a mode is a sphere that entails a whole array of territorial production, articulation and stabilisation. A mode captures a legal constitution, as precarious and in transition as it can be.

Such a conception could be called the modalisation of wine. Its usefulness lies in overcoming the dichotomy between analysis and judgement: each moment in the description and analysis of a wine entails an exercise of judgement, although not intended as a statement of personal preferences. Here, the distinctive aspect of judgement is to be found in its public nature, its visible presence in the animistic connection among humans. In other words, judgement is addressed to an audience, it is meant to be visible, ostensible, social, not as a further accidental determination - judgement is produced and then made public - but as an intrinsic aspect - publicness is the element in which judgement is produced. Thus, judgement (and its law) represents the largest category, into which wine analysis falls; and the preoccupation of sommeliers can be appreciated as the requirement to distinguish between two types of judgements: a structured, categorical judgement, on the one hand, and an unstructured, idiosyncratic judgement, on the other.

Sociologically speaking - as well as from a strictly lexical point of view - we can apply the notion of taste judgement to wine tasting because taste is not a simple set of preferences and appreciations, but rather a complex social relationship spanning the micro-scale situation at hand and the macro-scale world of winescape at large. 
The name of Pierre Bourdieu is often associated with the thesis that differences - not only in consumption styles and patterns, but also in taste preferences - are employed as items or affordances of class distinctions. The subjective correlate of this view is that taste works as a sixth sense, or a sense of cultural orientation: by recognising ourselves in certain schemes of perception and appreciation, we recognise ourselves as belonging to a certain class. Although not entirely wrong, this interpretation of Bourdieu's work is, to say the least, partial. In fact, Bourdieu's habitus-field theory envisaged to take into account not only the structural but also the generative dimension of taste. For Bourdieu 'classification systems would not have such crucial stakes were they not also contributing to shape classes themselves, adding to the effectiveness of the objective mechanisms the confirmation that derives from the images structured in ways that are consistent with classification. ${ }^{\text {'18 }}$ Between linguisticsymbolic structure, on the one hand, and the structure of the distribution of capital, on the other, there is always an interplay, an interstice, a loose space where 'the strategies designed to take advantage of the discordance between the real and the nominal, to appropriate words in order to appropriate the things they designate, or to appropriate things waiting to obtain the words that record them, make their appearance. ${ }^{19}$ Insofar as we are concerned, the structuralist thesis essentially identifies positions on

18 Pierre Bourdieu, La distinction. Critique sociale du jugement (Paris: Minuit, 1979): 474.

19 Ibid. 475. 
the basis of oppositions. As in Saussure's classic notion of langue, a taste option would be seen as a position that makes sense only insofar as it is distinguished and opposed to other options: you can only tell good taste on the basis of its difference from both common taste and bad taste - or, more accurately, good taste is nothing but that which is opposed to something else known as common, trivial, etc.

Yet, there is compelling evidence that, even keeping in mind the structural genesis of taste dispositions, taste cannot be explained as solely a matter of social distinction. This insight has gained ground in sociology over the last decade. Antoine Hennion and Geneviève Teil in particular have criticised the structuralist view on taste for its lack of recognition of the positive role that materiality plays in it. ${ }^{20}$ This new sociology of taste has pointed out that the act of engaging with a material object in activities as diverse as tasting a glass of good wine, listening to a piece of music, or opening a new climbing path on a cliff cannot be reduced to the positional differentiation of a subject from others. The differentiating function assigned to taste by the structuralist view is only one function among many other ongoing functions, and probably not even the most important one. Indeed, what matters most is not taste as opposed to lack of taste, but taste as a plurality of ways of being that are stimulated

${ }^{20}$ Antoine Hennion \& Geneviève Teil, 'Le goût du vin. Pour une sociologie de l'attention', in Véronique Nahoum-Grappe and Odile Vincent (Eds.) Le goût des belles choses (Paris: Éditions de la MSH, 2004). 
by a single material object. Taste represents the ways in which we engage in a variety of materials. Taste is a terrain, a territory.

In the difficult transition from taste to tastes, the issue is of course, more than ever, the contact with the object, but an object that opens up and becomes plural. Between a bunch of music notes and a work of art, between the physical wine and tasted wine, you pass through a sort of flaking, a series of mediations, you never swing over a dividing binary line. Tastes invite us not to turn away from the object and go looking for the real causes elsewhere, but to rethink the object that is in front of us as a possibility, as an attempt and a temptation, rather than as a sum of its parts. ${ }^{21}$

Such an argument is certainly not meant to lead us back to naive determinism: 'the object - continue Hennion and Teil - does not 'contain' its effects, as well known in aesthetics: taste is revealed precisely in uncertainty, variation, and the deepening of the effects that the product creates at the time and in the circumstances of its use.'

Here, the term 'object' must be placed rigorously in quotation marks. As we inspect more closely, we recognise that in practical activities such as wine tasting, music listening and rock climbing, there is no such thing as an object that stands in opposition to a subject. ${ }^{22}$ Rather, we are faced with a whole Gestalt, a configuration: a terrain,

21 Ibid.

22 For the case of climbing, see also Andrea Mubi Brighenti and Andrea Pavoni, 'Climbing the City. Inhabiting Verticality Outside of Comfort Bubbles', Journal of Urbanism: International Research on Placemaking and Urban Sustainability (2017). 
region or territory of encounters. It is upon this terrain, within this region, inside this territory, that we can define what is the actual focus of our practice, the problem field, the problématique, the Fragestellung as well as the playground, that is, the interest of it. Hence, with respect to wine, the importance of territory is doubled: not only is wine a territorial product, the product of a given territory or terroir, the unique ensemble of terrain and climate (pedoclimatic conditions); it is also a territory in itself: it contains the affordances that enter into a range of territorial compositions with the tasters. If we look at wine as the product of a territory, we are led to describe it as an object; but, if we look at it as a territory in itself, we might begin to appreciate it as an environment. Such is its dual legal constitution, which calls for a plural constitutionalism.

\section{Laying out the Problem Field}

Why can wine tasting be said to constitute a problem field? Etymologically, the word problem refers to something that is thrown before someone, or carried along the way. In this sense, the note of caution often recalled by sommeliers, according to which 'in tasting, you can never generalise,' refers precisely to a dynamic of knowledge that proceeds by problems, as opposed to deductive or syllogistic knowledge. Of course, a problem-orientation does not exclude guidelines for correct tasting. There are operative norms and preferential options in wine tasting. These guidelines determine the existence of a series of marked versus unmarked choices, whereby certain judgements are accepted as 'going without saying', less 
contestable and less surprising than others. But the training of novice sommeliers proceeds largely by examples and cases, to the point that one could never overstate the importance of experience and habit, of a personal history of dedication, devotion, of commitment to drinking. Even before defining a specific professional knowledge, experience and habit create an essential horizon of familiarity for the encounter, a preliminary and crucial taste for the taste.

From this perspective, wine could be characterised as a sensory problem. Not only the sense of taste, but all the five perceptual senses are involved in tasting. As a result, in this context the sense of taste stands by synecdoche for what is in fact a complete multi-sensorial practice. The sense of hearing must be attentive to capture how wine falls into the glass; sight must be able to describe the limpidness, colour, thickness or effervescence of wine; smell must grasp the intensity, persistence, complexity, quality and bouquet description of wine; taste and touch must interrogate its softness, hardness, texture, balance, intensity, persistence and quality, while all the senses must work together to determine evolution and harmony. The rich sensorium involved in and stimulated by tasting leads she who is exercising and improving her abilities as a taster towards a progressive refinement of one's sensorium. More and more refined abilities are proportionally called for in order to 'deal with' more and more refined and complex wines. A poor taster cannot make much of a rich wine. It is not just a matter of dispositional subjective qualities. What matters is the capacity to articulate the problem field in increasingly subtler and more nuanced 
ways. Such is the ability to create new encounters and new modes, to liberate new expressive materials and introduce new visibility thresholds between a range of continuous phenomena - the ability to make and remake the integral law of tasting.

To improve as a wine taster means, in other words, to make wine become visible, or visibilise as many of its qualities as possible. It means - following Gabriel Tarde's methodological recommendations - to move from 'similarities and repetitions of complex and confused masses to similarities and repetitions of detail, more difficult to grasp, but more precise, elementary and infinitely numerous as infinitesimal. ${ }^{23}$ All these similarities and repetitions, and above all these differences, are social insofar as they are material, rather than simply structural (or 'distinctive', in Bourdieu's sense). The social would not be possible without all the acts that inscribe, project and extract certain intensities and meanings into and from the materials at hand. The intuition of continuity is the payoff of animism.

In tasting, sensory abilities evolve with the ability to articulate one's feelings of the actual occasions, the ability to speak about wine - advice that is often repeated to novices. The correct usage of the conventional wine vocabulary (the grammar) must be supplemented with the capacity to move within the problem field with a certain familiarity (nonchalance and savoir-faire). The good sommelier is such because the nonchalance and savoirfaire (both untranslatable French words) with which she

${ }^{23}$ Gabriel Tarde, Les lois sociales (Paris: Synthelabo, 1999[1898]): 47. 
speaks about wine reveals her familiarity with and proximity to the expressive materials. Legal autochthony is what is at stake. Above, we have drawn attention to the 'intellectual pleasure' involved in tasting wine. Now we are perhaps better placed to see that, in fact, pleasure comes from accepting a challenge to judgement, which proves one's willingness to enter the game. The game of tasting also outlines a fundamental issue of style. We know, for instance, that wine descriptors are, more or less explicitly, evocative rather than referential (a descriptor such as 'peachy' does not mean that the same molecule is present in the peach and in the wine). The evocative dimension of judgement is not a neutral medium but something that stands out in comparison with the more or less - usually, less - developed skills of perception possessed by the general public of drinkers and non-drinkers alike.

\section{Leading Humans}

The sommelier is not simply living a personal experience with wine: she is also acting as a guide into the shared territorial experience of tasting. Today, the role the sommelier as an expert in 'wine communication' - or even a 'wine opinion leader' - is meeting increasing success. When we observe guided tasting sessions with lay participants, we notice that on these occasions the sommelier acts as an officiant and a veritable medium. Her officium consists in leading the other drinkers into a territory laid out by descriptions, analyses, debate and discussion. Wine tasting turns into - or rejoins - andragogy and psychagogy. The words chosen and used by sommeliers 
are hardly neutral; for example, once a cherry flavour has been evoked, named and put on the table, it will be in most cases recognised even by a novice. Because influences on judgement come from all sides, getting used to 'let the wine speak' thus also means to put oneself to test. One learns to move in a field that exists at the crossroads between the uniqueness of the actual encounter, and the repeatability - even, the seriality - of all wine encounters. The otherwise evanescent term style corresponds quite neatly to the trajectory drawn by this movement (we may also call it wayfaring, or reconnaissance) of social expression enacted through materials that are alive, like wine. Such is the wisdom of animism.

The paradox of training to taste probably lies in the fact that the novice fails to effectively describe or appreciate a wine not because she does not pay enough attention, but because she pays too much attention. The neophyte surrenders completely to the fullness of her immediate sensory experience. She is literally flooded with sensations and fails to introduce lines of discontinuity in the continuum of the experience. Descriptions, glosses, repertoires and classifications are meant to enable the taster to establish significant thresholds of differential visibility in this vast terrain. In order to be able to taste wine, one must keep at a certain meaningful distance from the wine - the correct distance necessary to make it thoroughly visible, or more insightfully so. Here is another way in which the law operates within this sensory domain. The visibilisation of wine can only be obtained thanks to the introduction of given a priori into the immanent uniqueness of the present experience. The sommeliers' tasting sheet 
(and scorecards are not different) is, from this point of view, a small Kantian masterpiece: transcendental in the precise philosophical sense, sheets and cards indicate the sets of dimensions that the encounter is necessarily bound to acquire, so that the 'only' thing that remains to be done is to make them relevant at the appropriate moment and in the appropriate way during the unfolding, actual occasion (how so, and how much).

Tasting is made possible by attention - more precisely, it is made possible by a careful strategy of visibilisation entailing perceptions and sensations. Visibility and movement are the constituents of this inner law of tasting. ${ }^{24}$ Rather than with perceptions, tasting is more precisely concerned with apperception in a Leibnizian sense, that is, perceptions made relevant upon a threshold of awareness and significance. In practice, wine tasting involves listening to one's body and its reactions. Mauss taught us that the body is the first technical tool of humanity; ${ }^{25}$ it is probably also the first legal tool. In tasting, one has to pay specific attention to how one's eye, nose and mouth react during the encounter with this wine: how, for instance, clarity and colour are revealed by tilting the glass at 45 degrees; how perfumes reach your olfactory mucosa directly through a short, sharp aspiration that creates a vortex of olfactory molecules; ${ }^{26}$ how saliva in one's mouth

24 I have explored the intimate connection between law and movement in Andrea Mubi Brighenti, 'Lines, Barred Lines. Movement, Territory and the Law', International Journal of Law in Context 6(3) (2010).

25 Mauss, Sociologie et anthropologie, $\$ \mathrm{VI}$.

${ }^{26}$ On the vibratory theory of smell, see in particular Luca Turin, The Secret of Scent: Adventures in Perfume and the Science of Smell (New York: Harper Collins, 2007). 
reacts with the acidic components of wine, and so on. This is how an encounter with wine is deployed. The technical instruments sommeliers employ - a decanter, a specially-shaped glass... - work as tools to produce apperception, sensory amplifiers that enable to magnify the visibility of the features one is trying to grasp and share with others. This Spinozean-Leibnizian situation can hardly be brought back into a classical Cartesian horizon. What emerges from tasting is not just one's own personal private encounter with wine: as in mimetic desire, someone else's encounter is simultaneously always involved. Since tasting is an intrinsically social activity, issues of authority and consent are pervasive; and yet, it would be unfair to regard them as omnipotent, resulting in a sheer truth-byconsent. It is simply not true that, just because no objectivity can be attained, everything and anything can be said about a wine, if one just sounds rhetorically convincing. Tasting involves the capacity to lay out and articulate a territory, mapping its geography, detailing its features and traits, defining its constitution.

Authority and consent are certainly part of the process, but the activity of tasting resides in the specification of the areas and the limits within which authority and consent matter. It is thus necessary to bring sensations and judgements into a shared public territory. This is why, as argued above, tasting can be appreciated as a kind of territorialisation properly understood - i.e. a territorial encounter in an ethological sense. Encounters are always characterised by their contingency and uniqueness. Encountering this or that wine is not a necessity (the encounter may not be), nor is it necessarily protracted (it may interrupt 
soon). Therefore, sensory analysis and sensory appreciation entail an apparently impossible task: a unique, contingent meeting - one which may not be repeated must be repeated - traced back and compared to former encounters, tracing a route towards further encounters to come. Tasting as wayfaring brings the encounter with this wine at hand into a series of virtual encounters with all possible wines, thus defining a peculiar tension between factual unrepeatability, on the one hand, and the axiological need for repetition, on the other. One's story with wine tasting lies at this crossroads.

The territorial aspect of the tasting experience becomes evident as soon as divergences between tasters appear. Given the experiential richness of tasting, and given the number of variables entailed in one encounter, such differences are actually quite common. Unlike more hierarchical contexts in which a single sommelier guides newbies, when a group of professional and semi-professional sommeliers who are basically peers make a joint tasting session, there is a general trend towards recomposing differences in judgement, in a joint effort towards unanimity. In other words, by attempting to converge on a set of shared views or, at least, articulating and disaggregating the elements of disagreement, sommeliers try to 'modalise' themselves. A shared mode must be gained or re-gained by re-territorialising the encounter among the sommeliers. While only rarely do trained sommeliers diverge in the evaluation of certain basic or simple aspects of wine, such as softness and hardness, more subtle assessments, such as nose-mouth correspondence, 
evolutionary state, and harmony, might turn out to be more difficult to recompose. There are several ways to get out of an interpretive impasse and reconcile judgmental divergences. Naïve scientific realism, which assumes the existence of an independent external truth which judgement might or might not mirror, does not apply here. At the other extreme, however, it is likewise not enough to speak of truth by consent. A mode must be modulated by tasters using the same materials and puzzling about similar issues of shared concern.

\section{Sailing the Sea of Wine}

Let us briefly recapitulate two fundamental reasons that prevent us from accepting the naive scientific realist image of taste judgement as a process of mirroring. In the first place, wine is not an object, but an expressive material that fundamentally exists in the dimension of becoming and in a conjoint territory. This fact precludes that it can be assessed in the same manner in which an object or tool (i.e., a glass) may be appraised. Especially when we face an aged wine, or an otherwise 'important' wine, we are dealing with a material in evolution. Immediately after pouring it, the bouquet is often too 'closed', and needs time to 'open up'. An equally crucial effect is played by the temperature of service, which makes the apperception of qualities range widely from one glass to another, from one moment to the next. These are just two variables that frame the encounter with wine as an unfolding process, instead of a punctual event. With Bergson, it is necessary 
to locate ourselves, not the order of time, but in the order of duration. ${ }^{27}$ Wine endures.

Furthermore, not only is wine dynamic along a diachronic axis. It is dynamic also synchronically. It often happens that, during a sufficiently large tasting session, all tasters assume that they are drinking exactly 'the same wine. True, they are drinking the same type of wine, produced by the same winemaker in the same year and the same vineyard. Hypothetical disagreements in evaluation are assumed to have been caused by substantively diverging judgements. In fact, it may turn out that, although the wine is indeed of the same type, tasters are drinking from different bottles - and, as well known, each bottle is 'an entirely different story' in terms of evolution, temperature, etc. A myriad of further details like this one, such as different glasses, uneven lighting of the room and so on, can produce infinite minor variations affecting the overall outcome of tasting. We need to think, not in terms of major drift, but again in terms of small perceptions to be brought within a single apperception.

The different micro-assemblages of singular elements that converge in a single session of tasting determine unique encounters for each taster, in each micro-location, at each specific moment in time. Modes, in other words, proliferate beyond the limits of control. All the rules and protocols are tentative tools to provide us with a compass for sailing in the sea of wine. Since, as said, wine cannot be reduced to an object, one way of appreciating it is to regard it as an environment. We are not facing wine,

27 Henri Bergson, Essai sur les données immédiates de la conscience (Paris: Presses universitaires de France, 1967[1889]). 
nor are we merely surfing on its surface; in fact, we are immersed in it as sailors, as we simultaneously struggle to probe it. Wine is an environment of individuation. As with every other passion, with every other one-dimensional fixation, one ingests what remains to be seen. In this sense, to turn again to Bergson - this time to the later Bergson of Matière et mémoire - wine is a multiplicity: it is the multiplicity that results from a heterogeneous material that cannot be reduced to either a numeric set or a degree on a numeric scale. ${ }^{28}$ What we find here is not a multiplicity of discontinuous, atomic, divisible states, but a multiplicity of a continuous flow taken in the range of a unifying memory: 'The qualitative heterogeneity of our successive perceptions of the universe - writes Bergson - is linked to the fact that each of these perceptions stretches for a certain lapse of duration, as well as to the fact that memory condenses an enormous multiplicity of stimulations which appear to us all together, albeit they are in fact successive.' In fact, it is as overlapping multiplicities secreting their own law that humans consociate, via their territorymaking explorations - making sense of their senses, that is, deploying the expression of animated materials.

\section{References}

Bennett, Jane. Vibrant Matter: A Political Ecology of Things. Durham, NC: Duke University Press, 2009.

Bergson, Henri. Essai sur les données immédiates de la conscience. Paris: Presses universitaires de France, 1967 (1889).

${ }^{28}$ Henri Bergson, Matière et mémoire. Essai sur la relation du corps a lesprit (Paris: Presses universitaires de France, 1968[1896]). 
- Matière et mémoire. Essai sur la relation du corps a l'esprit. Paris: Presses universitaires de France, 1968 (1896).

Boltanski, Luc and Thévenot, Laurent. On Justification: Economies of Worth. Princeton, NJ and Oxford: Princeton University Press, 2006 (1991).

Bourdieu, Pierre. La distinction. Critique sociale du jugement. Paris: Minuit (1979).

Brighenti, Andrea Mubi. 'On Territory as Relationship and Law as Territory'. Canadian Journal of Law and Society/Revue Canadienne de Droit et Société 21(2) (2006).

_. 'Lines, Barred Lines. Movement, Territory and the Law' In International Journal of Law in Context 6(3) (2010).

—. 'On Territorology. Towards a General Science of Territory'. In Theory, Culture \& Society 27(1) (2010).

_.'The Visible, Frontiers in Sociology (2017) https://www. frontiersin.org/articles/10.3389/fsoc.2017.00017/full

Brighenti, Andrea Mubi and Kärrholm, Mattias. 'Three Presents: On the Multi-Temporality of Territorial Production and the Gift from John Soane'. In Time \& Society (2016).

Brighenti, Andrea Mubi and Pavoni, Andrea. 'Climbing the City: Inhabiting Verticality Outside of Comfort Bubbles'. In Journal of Urbanism: International Research on Placemaking and Urban Sustainability (2017).

Deleuze, Gilles and Guattari, Félix. Mille Plateaux. Paris: Minuit, 1980.

Hennion, Antoine. Qu'est ce qu'un bon vin ? Ou, comment intéresser la sociologie à la valeur des choses. Paris: Centre de Sociologie de l'innovation. Working Paper 15, 1 March (2015).

Hennion, Antoine and Teil, Geneviève. 'Le goût du vin. Pour une sociologie de l'attention'. In Véronique Nahoum-Grappe and Odile Vincent (Eds.) Le goût des belles choses. Paris: Éditions de la MSH (2004).

Ingold, Tim. Being Alive. London: Routledge, 2011. 
Kärrholm, Mattias. 'The Animistic Moment. Clarice Lispector, Louis Kahn and a Reassembling of Materialities', In lo Squaderno 39 (2016).

—. 'The Materiality of Territorial Production a Conceptual Discussion of Territoriality, Materiality, and the Everyday Life of Public Space'. In Space and Culture 10(4) (2007).

Macdonald, Roderick A. 'Metaphors of Multiplicity: Civil Society, Regimes and Legal Pluralism'. In Arizona Journal of International \& Comparative Law 15(1) (1998): 71.

—. Lessons of Everyday Law. Montreal: McGill-Queen's University Press, (2002).

Mauss, Marcel. Sociologie et anthropologie. Paris: Puf, 1950.

Nietzsche, Friedrich. Untimely Meditations. Cambridge: Cambridge University Press, 1997 (1876).

Tarde, Gabriel. Les lois sociales. Paris: Synthelabo, 1999 (1898).

Turin, Luca. The Secret of Scent: Adventures in Perfume and the Science of Smell. New York: Harper Collins, 2007. 
